\title{
Genre of Folk Narratives as Rich Linguistic Resource in Acquiring English Language Competence for Young Learners
}

\author{
Prachishri Mishra \& SwayamPrabha Satpathy \\ Dept. of Humanities. ITER,Siksha O Anusandhan University. \\ Email:mishraprachishree7@gmail.com
}

\begin{abstract}
Folk narrative (tales) is the reflection of culture for a particular group of people, it's an amalgamation of the traditions common to a particular culture, subculture or group. These include tradition of narrating tales and proverbs. Ever since story telling has been a very alluring feature to understand a culture as well as helps in language learning. The frequent repetitions make them excellent for reinforcing new vocabulary and grammar. The natural rhythm that is associated with the tales is useful to work on stress, rhythm, and intonation in pronunciation. It is difficult for a learner to learn a language which is not his mother tongue. The cultural elements of folktales help to bridge common ground between cultures and bring out cultural differences. It develops cultural awareness that is essential if we are to learn to think in another language and understand the people who speak it. In this paper, it is analysed that can these folktales be used as a language learning tool? First of all, however, we would like to consider the definition of folktales and explain the hidden subtypes behind the term. Apart from looking at folk tales in general, this paper would take a look at their function it also discusses the reasons for using these in school. The main purpose of this study is to examine the role of folk narratives in teaching English to young learners as second language.
\end{abstract}

Key words: Language, Teaching, Learning, Folktales, Narrative, Culture.

\section{Introduction}

Language teaching through literature has already been an accepted approach. In the world of literature, folk literature is a type which is popular among the people across the globe. The reason behind the popularity is that it is easy to understand a folktale for its simple style, language and theme. However, literature itself draws attention of the readers and audience. And in the case of folk literature or folk tale this is truer. In the attempt of teaching English language through literature, learners are automatically drawn into the stream of learning involuntarily. Many linguists have advocated the use of folktales for language learning. Folk tales contain simple language and generally has a universal theme and it offers an amusing and deductive lesson to the readers and audience. Therefore use of folktales is an effective method of language teaching. It is possible to teach all the four skills of LSRW through the use of folktales.

A folktale is a story, myth or legend forming part of an oral tradition, does not have a single, identifiable author or writer and is or was passed down from one generation to the next. A folktale can change over time, be reshaped by modifications and was often changed with each retelling. As a result, there can be various versions of the same folktale. As a form of common folklore, folktales sugarcoat the hard lessons of life so as to give listeners or readers guidance about how they should behave. In this way, folktales help pass values and beliefs, traditions and

(C) AesthetixMS 2020. This Open Access article is published under a Creative Commons Attribution Non-Commercial 4.0 International License (http://creativecommons.org/licenses/by-nc/4.0/), which permits non-commercial re-use, distribution, and reproduction in any medium, provided the original work is properly cited. For citation use the DOI. For commercial re-use, please contact editor@rupkatha.com 
cultures across the generations. Popular examples of folktales are fairy tales (or fairytales), myths, legends, trickster tales, and tall tales.

\section{Literature review}

Folk tales form one of the genres of prose narratives. Ruth (1984, p.163) describes a folktale as, "The prose narrative genre" of oral literature while Bascom (1965, p. 4) says folktales are prose narratives regarded as fiction. Folktales may be set in any time and any place and in this sense they are almost beyond time and place. Folktales provide a good source for language teaching. Kachru (1991) asserts that folk tales sensitize the learners to language skills and should be implemented by the teacher in the language class. Apart from inculcating certain cultural values in the learners, folktales offer them a variety of speech forms which learners can imitate in improving greater communication efficiency. Courtney (1974) pointed to the educational values of folktales showing that there is a similarity between ancient thinking and the thought of childhood, which appeals to the adult learners because they evoke the elements of man's curious nature. The impressions that folktales create in the minds of children often last long. For example, May (1998) repeated that children experience the least difficulty when they have to retell their favorite folk tales, earlier read to them by their teacher. In this observation, the understandability of the folktale emerges from the familiarity of the folktales with students' experience From a very young age, children, in every country and of different races and ages, are told folktales from their home country by their parents, grandparents and even siblings. Many children hear these stories when very young and spend their childhood knowing these stories, folk songs and ballads.

Psychologists and educators have emphasized the vital role, stories play in the holistic development of children. Stories, especially folktales, provoke their imaginations and provide them with material from which children create their understanding of origins and purposes of the world. They tend to interpret form abstract concepts and values which may guide them to learn the language better. These stories stimulate their imagination about the world, allow them to visualize the world outside their homes. As language is culturally conditioned so an exposure to cultural knowledge enhances the understanding of language. Through folk stories, children learn about the values of family, friendship, hard work, honesty, faith, love, respect, safety and the cost of (often young children's) disobeying parents, betrayal, laziness, and so on. The folktales, which often have happy endings impart some moral learning as the story reflects good, the honest, the hard-working and brave win respect and love while the bad, lazy, and dishonest are punished, children develop their own understanding and appreciation for good, positive values and characteristics. Children can enjoy great works of folklore and discover their own role, identity and responsibility through folktale .

As a result of their exposure to folktales many children grow up with exciting dreams about becoming a hero or princess or fairy or magician as they hear the stories they are told. Stories, legends and fairy tales have become an important part of children's cognitive abilities and for many provide an indispensable part in the process of language learning.

\section{Materials and Methods}

\section{Folktales as a tool to teach Language}

Language teaching, based on literature, has been considered a common approach to promote both oral (listening and speaking) and literacy (reading and writing) skills. It involves the use of 
literary works of different types and scopes, ranging from prose and poems to folk chants and folktales to engage learners with meaningful, authentic input.

Through stories, learners acquire more than just language knowledge and usage and have opportunities to hear and use language in meaningful, engaging ways. Story-based teaching helps children develop an appreciation as well as an enjoyment of literature and supports the development of all of literacy, oral and social skills at the same time. Children learning through folktales can also develop their imagination and to make use of their creativity. They learn about negotiations and life values through the interactions and behavior of characters.

Stories from the oral traditions of many countries throughout the world provide learners with knowledge about social contexts which are familiar and also exciting. These stories portray contexts through which new language can be introduced and offer insights into different cultures, situations and scenarios in which people from their homeland or from a different country live and behave towards one another, settle conflicts and solve problems. The social contexts described in folktales also present learners with knowledge about how people from many countries thought and believed in earlier times, describing local social settings and the social expectations, thinking and reasoning which may be unique to a specific historical time. Such contexts add to the sense of expectation created by the events in stories and not found in other types of texts.

Language teaching, rest on literature, has been regarded to be a general criteria to aid both oral (listening and speaking) and reading and writing skills. It includes the use of composition of varied categories and horizons, stretching from prose and poems to folk songs and folk stories to involve children with significant and genuine input.

Stories, in general, and folktales, in particular, usher an overall approach to non-native language teaching and learning. With the help of stories, pupils receive more than just language and its usage. They have the opportunities to hear and apply language in relevant and productive ways. Story-based teaching helps learners blossom an appreciation for literature, thereby developing their attraction not only towards the piece of literature but also towards language as well. We can bluntly say that, apart from language acquisition, folk tales shapes the imagination and creativity in children. They learn about negotiations and other wheeling and dealing skills through the interplay and behavior of characters in the folk stories.

Narratives from the oral heritage of several countries all over the globe, furnish receivers with information about social contexts which are relatable and alluring. These stories represent situations with the help of which new language can be introduced. These contexts put forward insights into various cultures, circumstances and state of affairs. As a result, people from different countries live and behave towards one another with harmony, fix conflicts and resolve differences. The societal conditions discussed in folk narratives also make children aware of belief and thought process of people of different countries in earlier times. This includes regional social milieu, the social framework, thinking and reasoning which may be typical to a specific historical time. Such setting adds to the conjecture designed by the occurrence in narratives and not seen in other varieties of texts. This paper makes an attempt to validate the following objectives.

\section{Result and Discussion}

\section{Justification of Folktales for Language Acquisition for Young Learners `}

Learning is fun, pleasure giving and occupying for the children 
Usually when adults learn a non-native language, they have a specific purpose. But children may not have any specific purpose for foreign language learning. Therefore folk tales proved to be an appropriate tool for teaching English to non native young learners. Training the young ones with stories and folktales can make teaching fun filled and the learning becomes more impactful. The folk tales construct a world of Utopia, due to this; language acquisition turns playful and effective.

With the help of folklores, teachers are able to prepare assignments that are focused on cognitive development of children. These language activities are attention demanding and they build a relaxed and secured atmosphere for learning to take place. Young learners are inquisitive and they get fascinated by the fanciful setting, peculiar characters and the art of narration of the narratives. Hence they get involved in the tales narrated to them in the language class; discover the narratives attractive and enjoy by getting immersed in furnishing the assignment delegated by the instructor. A narrative like, Rapunzel or Red Riding Hood can engage young learners.

Folktales make relevant, valid and lucid input

Time and again different researchers have proved that, children are slanted towards meaning than form in a language. Therefore, meta cognitive analysis or instruction (e.g. "palace" is a noun and "big" is an adjective. Adjectives go before nouns so we say a big palace) in teaching a language for young non native trainees, is not advisable. The instructor should not present corrective feedback to the language misuse of the young one (e.g. "It's wrong. You should say I had dinner at $7.30 \mathrm{pm}$ yesterday, not I have dinner at $7.30 \mathrm{pm}$ yesterday because yesterday is in the past"). According to different cognitive development theories, children are active sense makers. In course of various phases of their mental growth, young ones are energetically involved it the exercise of creating meaning to comprehend. The example given below is a common scenario at second language or foreign language class rooms.

Learner: (a girl of 6 years): Can I go to play in the field with my friends?

Trainer: (stressing on form, in comparing "Can" and "May"): May I go to play in the field with friends?

Learner: But I said it first (thought the trainer wished to go before her.)

This example clearly shows children's inclination towards meaning than structure. Folk narratives supply relevant, valid and lucid input which help the teacher to train the language to the young ones, where they are taught the forms of language but without naming them. To make it simpler, we want to highlight that the language teachers teach them the forms of the language without telling them. They enjoy the story, focus on meaning and simultaneously learn the forms of language. When listening to the story, The Beauty and the Beast, they come across with the usage of tense, pronouns and gender.

...Beauty was a kind hearted girl. Her father loved her the most. She had two sisters. She loved to read. She never dressed well like her sisters. Her sisters were always busy in shopping fine dresses and hats for them. But Beauty was different. Her sisters always made fun of her, as her nose was always in the book

Here they learnt that Beauty was a girl so "she" is used for her. "Her" is used to refer to Beauty. Narration of past incident is also highlighted here.

Folk tales may contain a similar pattern that shows a moral or ethical value. These tales help children in comprehending the moral values and ethical practices present in the narrated story. 
Hence, we can conclude that, children learn value system; they are capable of differentiating between good and bad and use the lessons in their own lives along with learning a new language. Typical patterns and style found in most folk tales are:

a. Opening of a story: mostly we find the use of "once upon a time" or "long long ago" or "once there lived...."

b. Introduction of characters: Usually the characters in the folk tales are humans and animals. But sometimes there are mythical creatures. The characters are introduced clearly in the beginning to avoid confusion.

c. Representation of the surrounding: The back ground is clearly mentioned. This includes the weather of the setting (e.g.in the woods, in front of the palace, raining heavily, snow capped mountains, crystal clear water, bright sunny day)

d. Presentation of the issue to be discussed: The issue is discussed very vividly.

e. Sequence of occurrence: The occurrences are presented sequentially and it reaches a final conclusion.

f. The final solution and closing: Here the solution to problem is presented. The story comes to a happy ending where honesty is rewarded and the evil gets punished.

From these findings we can come to the conclusion that, children learn all these pattern used in the story. They get to know the art of introducing someone; they learn to present their own issues. They also learn positivity from the conclusion. Without being taught the narrative style, children can narrate stories after reading and listening to some of them. 3 . Tales render substantial, original word stock and introduce different types of discourse

Tales render substantial, original word stock and introduce different types of discourse

Tales present children with a wide variety of rich and authentic lexicon. This stock of words can be nouns like university, mother, father, king, queen, apple, dwarf, snow, fire, hut; verbs as jump, love, fight, swim, hate, sing, dance, play, cut; adverbs such as, merrily, happily, slowly, steadily, mercilessly, kindly and so on. The learners get to listen to meaningful chunks apart from learning these vocabularies. Read aloud story sessions help children in learning new patterns of the targeted language which they don't come across in their day to day life. These read aloud sessions facilitate children to develop their language competence by getting exposed to variety of authentic words, phrases and new patterns of the targeted language.

"Folktales typically include distinctive linguistic features such as novel words, onomatopoeic sounds, and repeated or paralleled phonological or grammatical patterns that create interesting rhythms... When folktales were written down and used as a way to introduce children to literature, words suitable for the child audience were often chosen." (Lwin, "Using Folktales", p. 75)

The discourses of tales that are presented in the classroom mostly use two of patterns language. They are: dialogues between characters and narration of series of events taking place in the story.

According to Cameron (2001), the publishers of folktales for children, use simple present tense to narrate different events or happenings. EFL curriculum, for the young learners, suggests introducing present tense at the beginning as it is easier for non native learners to learn. While describing a story through images, the trainers use present progressive tense. This method of training is more helpful and children grasp the language pattern faster. 
The folk narratives provide the young non native learners with exposure to discourses like narratives, dialogues, indirect speech and direct speech. Depending on the nature, focus and purpose of the assignment, trainers can alter the pattern of language of the original story. Indirect speeches can be converted to direct and some narrative part can be altered with dialogues.

Folk tales are easier to motivate children to learn English.

In case of learners, who have less interest in learning English, the language trainer should be smart enough to select teaching and learning activity based on the language experience using folk tales.

Taylor (2006) said that: "Students learn most effectively when they are working with materials they are attached to interested in, and they are most attached to and interested in materials that are about their own lives or they have composed themselves that is, some form of self-expression. Folktales are often an important part of people's heritage and cultural identity."

There are various guidelines to perform folktales in the classroom. One of them is to eliciting stories from the learners. This activity demands a reasonable amount of individual attention for each learner.

The details are given below:

(a) Ask the learner to tell you (the teacher) a short story from his or her culture.

(b) Then ask them to write it down. The teacher can correct the grammatical mistakes.

Give the story back to the student and have him or her read it. This helps the student with reading since the material is very familiar to them.

(c) Make the child revise and expand the story further. The student has to be the word master of his or her story.

(d) Some of the learners may be asked to narrate the story before the class, while the others are listening.

(e) Let the students give mutual correction with the wrong pronunciation. If the learners cannot get the correct pronunciation, then the teacher must tell them the right one.

(f) Ask for the moral of the stories to the learners and tell them to practice the good ones and avoid doing the bad ones in their lives.

By adopting this methodology, the children will learn many language skills in one activity; they are, listening, speaking, reading and writing. They also learn about grammar and pronunciation at the same time. The teacher may do the process completely or just some parts of it. This activity can be done in pairs or individually.

Folktales Encourage Imagination and Creativity among young learners 5.5

While the children, listen or read the stories a visual representation of the same goes on in the mind. They imagine the whole scenario of the story. Some of the narrative style of the tales encourages readers to predict about what is going to happen next. These narratives not only help in acquisition of the target language but also encourage imagination and creativity among children. The teachers can also boost the insightful development of the learners by asking them to present an alternative solution to the problem highlighted in the story or encourage them to speculate about what will happen next. Here the task of the trainer is to present the story in an 
interactive manner. The teacher should ask questions to the learners, creating curiosity in their mind.

Tales surprises the readers with a world of imagination filled with enchanting setting, miraculous incidents, mythical animals and magical spells. These features of the narratives are very alluring for children. Hence they learn the language faster by reading and listening to these stories. Their cognitive development is also accelerated along with language learning.

By comprehending the stories, innovative and enterprising ideas are flourished in children about a world which is very identical (because, dispute, distress and difficulties are present in their surrounding) and at the same time alienated (as occurrence of miracles, spells being caste, talking animals, demons and mythical creatures interact among them) to them. They have their own reasons and explanations for the happenings in the stories. Children are very judgmental. They have their peculiar opinions and vision about the characters narrated in the folktales. This particular characteristic can be manipulated by the trainers. They should stop at the right time within the story and ask questions to scratch the young minds to indulge in thinking. Questions like: "What do you think will happen next?" "Why did he say/do that?" "What you think will he do next?". These types of thought provoking activities are helpful for the cognitive development of young learners.

\section{Folktales as a tool for learning activities and introduction to many cultures}

Folk tales, typically carry two levels of meaning. The first one lies at the exterior layer of the story. It is usually a basic story, narrated referring and relating people or a person or incidents. Concealed beneath the literal story is mostly a moral that bring forth an entrance to the cultural cradle of the basic storyline. The trainers can take the help of these two layers of meanings of the story and teach the children how to read for meaning. Once learners clearly understand the literal meaning of the story, the trainers can design various activities related to the input and context that has been provided through the story. Palmer, Shackelford, Miller and Leclere (2006) suggested the below mentioned steps to facilitate children to have a greater understanding the story:

First Step: Trainers strike off the figurative language they plan students to comprehend.

Second step: Trainers tell exact meaning of difficult words that the students may fail to understand.

Third step: Trainers ask the literal meaning of difficult words to check whether the children know the meaning or not.

Fourth step: Trainers may assign tasks that can help children relate the importance of the phrase used in the story to their lives. Teachers can ask the learners to provide more instances, recognize the right images, to describe the expression, discuss and make predictions related to the story.

The interactive feature of folk narratives qualifies them to be used in language learning class rooms. If we think of stories to enhance comprehension and oral skills, then we must choose the stories, to be used, very carefully. Here the teachers should use adaptable and variable stories without any standard version. These sorts of stories can be molded as per the requirement of the learners.

Variation is a striking and sparking feature of folk tales. This feature has both linguistic and cultural application for language class rooms. The flexible texts of folk narratives can be designed and customized as per the requirement of the learners. Narratives render a display of 
many varieties of landforms and cultural pedigree. Most stories have various versions and many of them are international. But they have a local representation too where they present the colloquial language and the regional cultural context. "Ireland, Scotland, Wales, England, Cornwall, the US, Australia, New Zealand: all of these countries have stories that resemble those of other countries, with often identical narrative structures and themes, and yet contain their own special cultural references, which can be revealing for the language student" (Masoni,2018).Let us examine a passage from a version of RashinCoatie the Scottish Cinderella by:

"Once, a long time ago, there was a gentleman had two lassies. The oldest was ugly and ill natured, but the youngest was a bonnie lassie and good; but the ugly one was the favorite with her father and mother. So they ill used the youngest in every way, and they sent her into the woods to herd cattle, and all the food she got was a little porridge and whey."

Well, amongst the cattle was a red calf, and one day it said to the lassie, "Gee that porridge and whey to the doggie, and come wi' me". So the lassie followed the calf through the wood, and they came to a bonnie hoosie, where there was a nice dinner ready for them; and after they had feasted on everything nice they went back to the herding". (Douglas, 1901, p. 17)

This is the famous story of "Cinderella" where many portions are modified as per the culture and the provincial tongue. In this Scottish version the magic helper is a "calf" but not an old lady or a fairy. The heroine is described as eating forcibly a Scottish tasteless dish called porridge made up of whey. Scot words such as "lassie" for girl, "bonnie" for beautiful or "hoosie" for house. Components of the domestic tongue and regional culture saturate the plot of the narrative without modifying its general structure, which can be effortlessly connected to the more widely spreaded versions of "Cinderella".

Numerous cultural references can be presented to the learners through narratives that would be tough to establish and contextualize. "Cultural fragments and dialect words always catch student's attention and set them thinking about similarities and differences in their own cultures, thus generating comparative thinking both about the language and its society. The common structure and motifs also have important cognitive implications for our multi-cultural classrooms: with properly chosen stories, students will recognize familiar structures they know well and know what to expect from. Activating a story in a foreign language is not a simple task: it involves cultural translation as much as verbatim translation; it requires that the audience and listener develop and share verbal and nonverbal patterns of interaction to arrive at a common understanding. ." (Masoni, 2018).

\section{Folk tales help learners young acquire the new language by natural repetitions}

The narration of a story is a dialogue between the narrator and the hearer where they both work as partners in acquisition of the target language. The teller goes on repeating the new structure and vocabulary of the story. They ask the children to repeat the utterance after them. By listening to the repeated sounds (vocabulary), the learners establish a relation between the words they hear and repeat and their meaning. However, the entire act of repetition has to be innovative and interesting. If the activities fail to attract the audience, they lose interest and language learning is highly affected. Here the teacher should keep in my mind that not all folktales are worth repeating. The tales that have simpler structure should be selected. Although not all folktales repeat structures or vocabulary, it is not uncommon to find those that repeat words or sentences can be modified to include repetitions in a meaningful, natural manner. This is often referred as "parallelism" (Thi and Nhung, 2016). 


\section{Conclusion}

According to Licia Masoni, "oral narratives provide an organic and holistic means of introducing language and language use to our students and for this reason context is most important. We can rely on our students to provide that context, by enabling them to be the experts of their own stories. From fairy tales to contemporary legends, folk narratives in the English language are steeped in the oral traditions of the people they voice. As such, they constitute invaluable material in the foreign language classroom, both in terms of language and in terms of cultural references. Everything in folk narrative-from the narrative structures, to the language employed and the themes developed-strives towards comprehension, visualization and memorization". Narratives present interesting and alluring stories which has a lasting impact on the psyche of children. It penetrates deep into the cognitive being of the young learners. "Their thematic appeal, together with the powerful messages they convey, fosters identification and opens up the way for positive affective responses that enhance the foreign language learning experience. From fairy tales to jokes and conversational narratives, folk narratives can provide invaluable linguistic material for the EFL classroom across various educational settings" (Masoni, 2018).

Use of folktale is a powerful and effective way of learning language in general and foreign language in particular. For young learners folk narratives are very effective as "they present authentic, rich, meaningful input and help the process of acquiring the language competence. Children can benefit immensely from stories which provide a context for them to create meaning from the language used in it. Carefully selected or modified folktales also have features such as parallelism and meaningful, natural and rhythmic repetition of language"(Thi and Nhung, 2016). This escalates learners' capabilities to acquire the target language in an informal manner. Stories enable the trainer to conduct many interesting assignments that are related to various "learning styles" for learners. These narratives boost creativity and insightful skills in children resulting in broadening their vista regarding people of different parts of the world.

Folk tales being a part of an "oral tradition", the stories are passed from generation to generation orally. People hear and remember. "Language lessons have their own purpose and objectives and folktales, in their original form, often do not fit well with language teaching objectives. Therefore, folktales will often require further modification for the purposes of language teaching and so that they closely correspond with the objectives of specific lessons" (Thi and Nhung, 2016) and suit the level of mental, psychological and linguistic development of young language learners ,there by elevating their target language learning exercise. Since young learners are passionate about stories, learning can be enjoyable if teachers make the necessary modification required to make the story interesting for them.

Finally in this paper we conclude that, using folktales in the language teaching will make the learners more motivated in the teaching and learning process. By introducing stories with extremely pictorial language in the classroom, we provide strong contexts for words and facilitate their retrieval and that of other words associated with them. Folklorists have for a long time been interested in how storytellers rely on those images to remember the stories they tell (MacDonald, 1978). Their thematic appeal, together with the powerful messages they convey, fosters identification and opens up the way for positive affective responses that enhance the foreign language learning experience. From fairy tales to jokes and conversational narratives, folk narratives can provide in valuable linguistic material for the second language classroom. 


\section{References}

Bauman, R. (1975). Verbal Art as Performance. American Anthropologist New Series, 77: 290-311.

Bauman, R., \& Briggs, C. L. (1990). Poetics and performance as critical perspectives on language and Social life. Annual Review of Anthropology, 19:59-88.

B. Bettelheim. (1976). The uses of enchantment: The meaning and importance of fairy tales. New York: Knopf.

B. C. Palmer and M. A. Brooks.( 2004).Reading until the cows come home: Figurative language and reading comprehension,Journal of Adolescent \& Adult Literacy, 47: 370-379.

B. C. Palmer, L. Sun and J. T. Leclere.(2012). Students learn about Chinese culture through the folktale YehShen. Emphasizing figurative language interpretation,Promising Practices, Winter volume:49-54.

B. C. Palmer, V. S. Shackelford, S. C. Miller and J. T. Leclere. (2006). Bridging two worlds: Reading comprehension, figurative language instruction, and the English-language learner, Journal of Adolescent \& Adult Literacy, 50, 258-268.

C. T. Linse. (2005). Practical English language teaching: Young learners. New York: McGraw-Hills Company.

J. Gold and A. Gibson.(2001). Reading aloud to build comprehension. Retrieved from http://www.readingrockets.org/article/343.

L. Cameron.(2001) .Teaching languages to young learners. UK: Cambridge University Press.

L. L. Ramírez.(1999). The story of Proyecto Papan-folktales and their potential for foreign language education, Foreign Language Annals, 32: 363-371.

L. M. Crawford-Lange and D. Lange. (1984). Doing the unthinkable in the second language classroom: A process for the integration of language and culture, in Teaching for proficiency, the organizing principle, T. Higgs, Ed. Lincolnwood, IL: National Textbook Company: 139-177.

M. J. Worthy and J. W. Bloodgood.(1993). Enhancing reading instruction through Cinderella tales, The Reading Teacher, 46: 290-301.

P. Mckay.(2006). Assessing young language learners. Cambridge: Cambridge University Press.

R. A. Kaminski.(2002). Cinderella to rhodolphus, in The dragon lode, 31-36.

R. Gholson and C-A. Stumpf.(2005). Folklore, literature, ethnography, and second-language acquisition: Teaching culture in the ESL classroom, TESL Canada Journal, 22:75-91.

R. Isbell, J. Sobol, L. Lindauer and A. Lowrance.(2004). The effects of storytelling and story reading on the oral language complexity and story comprehension of young children. Early Childhood Education journal, 32: 157-163.

T. H. N. Pham et al.,( 2015). Using folk stories to teach English to young language learners. Hue, Vietnam: Hue University Press.

W. A. Scott and L. H. Ytreberg.(2010). Teaching English to children. New York: Longman. 